\title{
Associations of pathogenic mutations responsible for breast cancer risk with histology and immunohistochemistry in Romanian population
}

\author{
Iulian Gabriel Goidescuํ, Dan Tudor Eniu ${ }^{2 *}$, Gabriela Valentina Caracostea ${ }^{1}$, \\ Gheorghe Cruciat $^{1}$, Florin Stamatian ${ }^{1}$
}

\author{
1. Department of Obstetrics and Gynecology I. University of Medicine and \\ Pharmacy "Iuliu Haţieganu”, Romania \\ 2. Department "Surgical oncology and Oncological Gynecology", University of \\ Medicine and Pharmacy "Iuliu Haţieganu”, Romania
}

\begin{abstract}
Introduction: Breast cancer is the most common cancer in women worldwide, and Romania makes no exception from this trend. Genetic screening for Hereditary Breast and Ovarian Cancer began to be used on a larger scale after the introduction of Next Generation Sequencing.

The aim of this study was to assess the association of deleterious mutations responsible for breast cancer with histopathological and immunohistochemical prognostic factors and to identify some genetic variants in the BRCA1 and BRCA2 genes.

Method: 80 patients with breast cancer and negative genetic test or pathogenic variants on BRCA1/2, TP53, PALB2, CHEK2, ATM genes were included. All the cases had a prior histological diagnosis and complete immunohistochemical features. The genetic testing was conducted through a multigene panel.

Results: $65 \%$ of patients had a deleterious mutation on BRCA genes. In $97.5 \%$ of cases the histology was invasive ductal carcinoma. Significant differences were identified between BRCA1 group and negative mutation group regarding estrogen receptor $(E R)(p=0.0051)$, progesterone receptor $(P R)(p=0.0004)$ and Ki67 $(p=0.001)$. Seven breast cancer patients had BRCA1 c.3607C $>$ T variant, which was statistically significantly associated with triple- negative breast cancer $(p<0.0001)$. Of the 7 cases diagnosed with BRCA 2 mutations we identified the c.8755-1G>A variant in 3 cases and the c.9371A $>$ T variant in 3 cases.

Discussion and conclusion: Our study confirmed the association of BRCA1 mutations with negative ER, $P R$ or triple negative breast cancer (TNBC). Description of BRCA1 c.3607C $>$ T mutation for the first time in Romanian population and its association with TNBC will need further investigation.
\end{abstract}

Keywords: pathogenic variants, hereditary breast and ovarian cancer syndrome, breast cancer, triple-negative breast cancer

Received: 25 $5^{\text {th }}$ September 2017; Accepted: $4^{\text {th }}$ December 2017; Published: $5^{\text {th }}$ January 2018

*Corresponding author: Dan Tudor Eniu, University of Medicine and Pharmacy "Iuliu Haţieganu" Cluj Napoca, Romania. E-mail: tudor.eniu@umfcluj.ro 


\section{Introduction}

Breast cancer is the most common malignancy in women worldwide and the second cause of death by neoplasia, with an estimated annual incidence of 66.2/ 100000 and a mortality rate around 21.6 deaths/ 100000 in Romania [1].

For the first time in the $90 \mathrm{~s}$, mutations in two genes known as BRCA1 (BRest CAncer) [2] and $B R C A 2$ genes [3] were associated with breast cancer risk. Since then more genes have been associated with breast cancer risk, with an explosive increase after the introduction and large scale use of Next Generation Sequencing (NGS) [4].

In addition to BRCAI and BRCA 2 mutations, other genes have been incriminated for breast cancer predisposition, some with high penetrance, such as TP53, PTEN, STK11, CDH1, others with moderate penetrance, like $P A L B 2$, $C H E K 1, A T M$, recent studies assigning an increasing importance in the HBOC pathogenesis of the latter [5].

The technological progress in the last decade has also helped in obtaining a complete immunohistochemistry of the histopathological specimens in a shorter time. A complete histopathological diagnosis with related immunohistochemistry may guide the medical conduct towards a genetic testing that will lead to a more accurate diagnosis and an optimal treatment [6].

The most well-known association between histology, immunohistochemistry and genetic determinism is that of BRCA1 gene mutations with triple negative breast cancer forms (TNBC) - negative Estrogen receptors (ER), negative Progesterone receptors (PR) and negative Human epidermal growth factor 2 receptor (HER2) [6, 7].

The importance of this association between BRCA1 mutations and TNBC forms lies in the fact that patients with TNBC have an increased risk of relapse, a poor long term prognosis due to insensitivity to endocrine therapy and anti-HER2 molecular therapies [8]. However, knowing the association of $B R C A 1$ mutations with TNBC can open new opportunities for treatment using the platinum agents or poly ADP ribose polymerase inhibitors (PARP inhibitors) [9].

In medical literature, there is data regarding the association of less common mutations (e.g. TP53, PALB2, ATM) with certain histological and immunohistochemical features, but the small number of cases and the heterogeneity of the studied population makes it more difficult to establish a precise correlation [10].

The aim of this study was to assess the association of high and moderate penetrance pathogenic mutations responsible for breast cancer (BRCA1, BRCA2, TP53, PTEN, STK11 CDH1, PALB2, ATM, CHEK2) with specific histopathological and immunohistochemical prognostic factors. The secondary objectives were: to describe the frequency of some genetic variants in the BRCA1 and BRCA2 genes; to determine whether these variants are similar to those in the neighboring countries of Romania (the Eastern European region); and to analyze their correlation with tumor characteristics.

\section{Material and Method}

\section{Ethics}

This descriptive retrospective study was conducted with the approval no.369 / 14.10.2016 of the ethics committee of "Iuliu Haţieganu" University of Medicine and Pharmacy, Cluj-Napoca, Romania. We obtained the informed consent of all patients on the first medical evaluation.

\section{Patients}

We enrolled 80 of 108 consecutive patients diagnosed with breast cancer who were addressed for the oncological examination in Oncosurg Surgical Oncology Clinic, from Cluj-Napoca between January 2015 and December 2016 and met the 2016 National Comprehensive Cancer Network (NCCN) criteria for genetic testing [11]. All the patients had a histopathological diagnosis carried out through a Tru-Cut Needle Biopsy in our clinic. 
Of the 28 patients excluded 10 had Variants with Unknown significance (VUS) in the studied genes, 3 had pathogenic mutations in low penetrance genes (RAD50, MLH1, MSH6+MUTYH) 15 had mutations in other genes (3 mutations in each $B A R D 1$ and $P M S 2$ genes, 2 mutations in each of the RAD 50, BLM genes and 1 mutation in each MLH1, MSH2, MSH6, RAD51C, MEN1 genes).

\section{Histopathology and immunohistochemistry}

The pathological examination was conducted in the same laboratory (Santomar Oncodiagnostic) and included the histological type, grade, lymphovascular space invasion and immunohistochemical (IHC) evaluation of estrogen receptor (ER) status, progesterone receptor (PR) status (Allred score), human epidermal growth factor 2 receptor (HER2) gene expression and Ki67 proliferation index.

The histopathological examination was performed with hematoxylin and eosin stain. The immunohistochemical tests were performed using 4-micron-thickness sections of histological specimens fixed in 10\% neutral buffered formalin (NBF). Staining was done automatically on a BenchMark ULTRA system (Ventana TM, Roche), using an OptiView ${ }^{\mathrm{TM}}$ amplification kit.

The following primary antibodies were used: ER (clone 6F11, Novocastra ${ }^{\mathrm{TM}}$ at a $1 / 40$ dilution, an antigen exposure with the $\mathrm{CC} 1$ solution); RP (clone 16, Novocastra ${ }^{\mathrm{TM}}$ at a $1 / 250$ dilution, an antigen exposure with the CC1 solution); HER2 (clone 4B5, RTU, Ventana ${ }^{\mathrm{TM}}$ an antigen exposure with the CC1 solution); Ki67 (clone MIB1, $1 / 600$ dilution, an antigen exposure with the CC1 solution); E-cadherin (clone 35B5, Novocastra $^{\mathrm{TM}} 1 / 50$ dilution, an antigen exposure with the $\mathrm{CC} 1$ solution).

In cases with HER2 ambiguity (2+) determined by immunohistochemistry, chromogenic or fluorescence in situ hybridization was carried out. Chromogenic dual In Situ Hybridization
(DISH) was performed automatically on a BenchMark ULTRA system (Ventana ${ }^{\mathrm{TM}}$, Roche) with

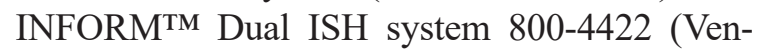
tana $\left.{ }^{\mathrm{TM}}\right)$ kit. Fluorescense In Situ Hibridization (FISH) was performed using a Path vision HER-2 DNA Probe Kit from ABBOTTM. The FISH technique was performed with CytoVision DM2500 capture station from Leica Biosystems ${ }^{\mathrm{TM}}$.

\section{Genetic testing}

Each patient was approached for genetic testing after the histological diagnosis, prior to any other oncological treatments (chemotherapy or hormonal therapy). Genomic DNA was prepared from 5-10 ml of peripheral blood.

Multigene panel test includes the analysis of 25 genes: $A T M, B A R D 1, B L M, B R C A 1, B R C A 2$, BRIP1, CDH1, CHEK2, FAM175A, MEN1, MLH1, MRE11A, MSH2, MSH6, MUTYH, NBN, PALB2, PMS2, PTEN, RAD50, RAD51C, RAD51D, STK11, TP53, XRCC2. Genomic DNA obtained from the submitted sample was enriched for targeted regions of 25 genes involved in hereditary predisposition to cancer. Sequencing was carried out using Illumina technology (MiSeq System). All clinically significant observations were confirmed by orthogonal technologies. Orthogonal technologies are used to ensure that variant calls are independently confirmed and thus accurate [12]. All targeted regions were sequenced with $\geq 100 \mathrm{x}$ depth. This assay targets all coding regions of the indicated transcript, 10 base pairs of flanking intronic sequence, and specific intronic and intragenic genomic regions demonstrated to be causative of disease. However, for some genes only targeted loci were analyzed. The presence of large genomic rearrangements was investigated using MLPA (Multiplex Ligation - dependent Probe Amplification to Probe Amplification - highly specific chromosome region of interest; [13]).

All the genetic tests were conducted in GeneKor Laboratories, Greece. 


\section{Statistics}

Data are expressed as median and interquartile range $((\mathrm{Q} 1-\mathrm{Q} 3)$ where $\mathrm{Q} 1$ = first quartile, $\mathrm{Q} 3$ = third quartile range) for continuous variables that proved not to follow the normal distribution (tested with Shapiro Wilk test). The comparisons between groups on quantitative data not normally distributed were analyzed with Mann-Whitney test. We used absolute and relative frequencies to express categorical comparisons and Chi-square family tests for proportion to compare frequencies between different groups. A p value of less than 0.05 was considered to indicate statistical significance; all tests were two-tailed. The statistical analysis was performed with the statistical package Statistic for Windows (v. 8, StatSoft, Tusla, USA). Graphical representation of the distribution of immunohistochemical characteristics by group was done using the approach proposed by Weissgerber et al. [14].

\section{Results}

During the analyzed period, 108 patients with breast cancer were eligible for testing and 80 were included in the study (41 with deleterious variants and 39 without any mutation). Of the 41 breast cancer cases, 26 were caused by mutations in the $B R C A 1$ and $B R C A 2$ genes, the rest being due to mutations in the genes CHEK2 (6 cases), PALB2 (5 cases), ATM ( 2 cases) and TP 53 (2 cases).

Patient and tumor characteristics according to mutation are summarized in Tables 1 and 2.

We did not identify any pathogenic variants in PTEN, STK11 and CDH1 genes, but only VUS variants which were excluded because of the uncertain risk of breast cancer.

Patients with deleterious variants were diagnosed more frequently with poorly differentiated tumors $(\mathrm{G} 3)(\mathrm{p}=0.0050)$ compared to those without mutations which had more commonly well-differentiated forms of breast cancer (G1) $(\mathrm{p}=0.0120)$ (Table 2).

Table 1. Characteristics of the patients and frequency of family history of breast cancer

\begin{tabular}{|c|c|c|c|c|c|c|c|}
\hline Characteristic & $\begin{array}{c}\text { BRCA1 } \\
(n=19)\end{array}$ & $\begin{array}{c}\text { BRCA2 } \\
(n=7)\end{array}$ & $\begin{array}{c}\text { CHEK2 } \\
(n=6)\end{array}$ & $\begin{array}{c}\text { PALB2 } \\
(\mathrm{n}=5)\end{array}$ & $\begin{array}{l}\text { TP53 } \\
(n=2)\end{array}$ & $\begin{array}{l}\text { ATM } \\
(n=2)\end{array}$ & $\begin{array}{c}\text { Negative } \\
(n=39)\end{array}$ \\
\hline Age (years old) ${ }^{a}$ & $\begin{array}{c}43.00 \\
(35.00- \\
48.00) \\
\end{array}$ & $\begin{array}{c}41.00 \\
(35.50- \\
43.50)\end{array}$ & $\begin{array}{c}45.00 \\
(44.25- \\
55.50)\end{array}$ & $\begin{array}{c}50.00 \\
(31.00- \\
60.00) \\
\end{array}$ & $\begin{array}{c}37.00 \\
(35.00- \\
45.25)\end{array}$ & $\begin{array}{c}48.00 \\
(43.00- \\
53.00) \\
\end{array}$ & $\begin{array}{c}41 \\
(36- \\
48.5) \\
\end{array}$ \\
\hline \multicolumn{8}{|l|}{ Living area ${ }^{b}$} \\
\hline Urban & $16(84.21)$ & $4(57.14)$ & $5(83.33)$ & $4(80.00)$ & $2(100)$ & $2(100)$ & $28(71.80)$ \\
\hline Rural & $3(15.79)$ & $3(42.86)$ & $1(16.66)$ & $1(20.00)$ & $0(0.00)$ & $0(0.00)$ & $11(28.20)$ \\
\hline BMI, $\mathrm{kg} / \mathrm{m}^{2}$ a & $\begin{array}{l}25.10 \\
(22.09- \\
30.13)\end{array}$ & $\begin{array}{c}23.67 \\
(21.83- \\
25.07)\end{array}$ & $\begin{array}{c}22.83 \\
(22.65- \\
23.19)\end{array}$ & $\begin{array}{l}25.07 \\
(23.53- \\
26.12)\end{array}$ & $\begin{array}{c}21.20 \\
(19.94- \\
30.24)\end{array}$ & $\begin{array}{c}32.18 \\
(30.24- \\
34.12)\end{array}$ & $\begin{array}{l}23.39 \\
(21.20- \\
26.26)\end{array}$ \\
\hline \multicolumn{8}{|l|}{ BMI class ${ }^{b}$} \\
\hline Overweight & $5(26.32)$ & $2(28.57)$ & $0(0.00)$ & $3(60.00)$ & $0(0.00)$ & $1(50.00)$ & $11(28.21 \%)$ \\
\hline Obese & $5(26.32)$ & $0(0.00)$ & $1(16.67)$ & $0(0.00)$ & $0(0.00)$ & $1(50.00)$ & $2(5.13)$ \\
\hline \multicolumn{8}{|l|}{$\begin{array}{l}\text { Breast cancer: } \\
\text { family history }{ }^{\mathrm{b}}\end{array}$} \\
\hline Mother & $8(42.11)$ & $2(28.57)$ & $3(50.00)$ & $1(20.00)$ & $0(0.00)$ & $1(50.00)$ & $12(29.27)$ \\
\hline Sister & $1(5.26)$ & $1(14.29)$ & $0(0.00)$ & $2(40.00)$ & $0(0.00)$ & $0(0.00)$ & $2(4.88)$ \\
\hline Grandmother & $3(15.79)$ & $1(14.29)$ & $2(33.33)$ & $2(40.00)$ & $0(0.00)$ & $1(50.00)$ & $8(20.51)$ \\
\hline Aunt & $3(15.79)$ & $2(28.57)$ & $1(16.67)$ & $1(20.00)$ & $0(0.00)$ & $2(100.00)$ & $6(15.38)$ \\
\hline
\end{tabular}

a: median (Q1-Q3), where Q = quartile (1 = first, 3 = third $)$

b: no. of cases $(\%)$

BMI - body mass index; Overweight: $\mathrm{BMI}=25-29.9 \mathrm{~kg} / \mathrm{m}^{2}$, Obese: $\mathrm{BMI}>30 \mathrm{~kg} / \mathrm{m}^{2}$ 
Table 2. Tumor histological features according to gene mutations

\begin{tabular}{cccccccc}
\hline Characteristic & $\begin{array}{c}\text { BRCA1 } \\
(\mathbf{n = 1 9 )}\end{array}$ & $\begin{array}{c}\text { BRCA2 } \\
(\mathbf{n}=\mathbf{7})\end{array}$ & $\begin{array}{c}\text { CHEK2 } \\
(\mathbf{n}=\mathbf{6})\end{array}$ & $\begin{array}{c}\text { PALB2 } \\
(\mathbf{n}=\mathbf{5})\end{array}$ & $\begin{array}{c}\text { TP53 } \\
(\mathbf{n = 2})\end{array}$ & $\begin{array}{c}\text { ATM } \\
(\mathbf{n}=\mathbf{2})\end{array}$ & $\begin{array}{c}\text { Negative } \\
(\mathbf{n}=\mathbf{3 9})\end{array}$ \\
\hline Localization & & & & & & & \\
$\quad$ Left & $7(36.84)$ & $5(71.43)$ & $2(33.33)$ & $2(40.00)$ & $1(50.00)$ & $2(100.00)$ & $17(43.59)$ \\
Right & $12(63.16)$ & $2(28.57)$ & $2(33.33)$ & $3(60.00)$ & $1(50.00)$ & $0(0.00)$ & $22(56.41)$ \\
Bilateral & $0(0.00)$ & $0(0.00)$ & $2(33.33)$ & $0(0.00)$ & $0(0.00)$ & $0(0.00)$ & $0(0.00)$ \\
\hline Tumor Focality & & & & & & \\
Multifocal & $2(10.53)$ & $2(28.57)$ & $2(33.33)$ & $0(0.00)$ & $1(50.00)$ & $0(0.00)$ & $9(23.08)$ \\
Unifocal & $17(89.47)$ & $5(71.43)$ & $4(66.67)$ & $5(100.00)$ & $1(50.00)$ & $2(100.00)$ & $30(76.92)$ \\
\hline Grade & & & & & & \\
G1 & $0(0.00)$ & $1(14.29)$ & $1(16.67)$ & $0(0.00)$ & $0(0.00)$ & $0(0.00)$ & $10(25.64)$ \\
G2 & $6(31.58)$ & $4(42.86)$ & $3(50.00)$ & $1(20.00)$ & $2(100.00)$ & $1(50.00)$ & $20(51.28)$ \\
G3 & $13(68.42)$ & $2(42.86)$ & $2(33.33)$ & $4(80.00)$ & $0(0.00)$ & $1(50.00)$ & $9(23.08)$ \\
\hline Histology & & & & & & \\
IDC & $19(100.00)$ & $7(100.00)$ & $4(66.67)$ & $5(100.00)$ & $2(100.00)$ & $2(100.00)$ & $35(89.74)$ \\
ILC & $0(0.00)$ & $0(0.00)$ & $1(16.67)$ & $0(0.00)$ & $0(0.00)$ & $0(0.00)$ & $0(0.00)$ \\
DCIS & $0(0.00)$ & $0(0.00)$ & $1(16.67)$ & $0(0.00)$ & $0(0.00)$ & $0(0.00)$ & $4(10.26)$ \\
\hline
\end{tabular}

IDC = invasive ductal carcinoma; ILC = invasive lobular carcinoma; DCIS = Ductal carcinoma in situ $\mathrm{n}=$ no. of cases $(\%)$

The most poorly differentiated tumors (G3) were in the BRCA1 mutation group $(68.42 \%)$ and especially in the PALB2 group (80\%) (Table 2).

In the group of patients with deleterious variants the prevalent histology was invasive ductal carcinoma in $97.5 \%$ of cases and in one case the histology was invasive lobular carcinoma diagnosed in a CHEK2 mutation carrier with bilateral breast carcinoma.

A quarter of patients with CHEK2 mutations had bilateral carcinoma ( 2 out of 6 patients) (Table 2).

Table 3. Immunohistochemical characteristics of breast tumors according to gene mutations

\begin{tabular}{|c|c|c|c|c|c|c|c|}
\hline Characteristic & $\begin{array}{c}\text { BRCA1 } \\
(n=19)\end{array}$ & $\begin{array}{c}\text { BRCA2 } \\
(n=7)\end{array}$ & $\begin{array}{c}\text { CHEK2 } \\
(n=6)\end{array}$ & $\begin{array}{c}\text { PALB2 } \\
(n=5)\end{array}$ & $\begin{array}{l}\text { TP53 } \\
(n=2)\end{array}$ & $\begin{array}{l}\text { ATM } \\
(n=2)\end{array}$ & $\begin{array}{c}\text { Negative } \\
(n=39)\end{array}$ \\
\hline $\operatorname{ER}(\%)^{a}$ & $\begin{array}{c}0.00 \\
(0.00- \\
77.50)\end{array}$ & $\begin{array}{c}100.00 \\
(85.00- \\
100.00)\end{array}$ & $\begin{array}{c}90.00 \\
(75.00- \\
93.75)\end{array}$ & $\begin{array}{c}80.00 \\
(0.00- \\
100.00)\end{array}$ & $\begin{array}{c}30.00 \\
(15.00- \\
69.50) \\
\end{array}$ & $\begin{array}{c}64.00 \\
(47.00- \\
81.00)\end{array}$ & $90(15-100)$ \\
\hline $\operatorname{PR}(\%)^{\mathrm{a}}$ & $\begin{array}{c}0.00 \\
(0.00- \\
0.00) \\
\end{array}$ & $\begin{array}{c}40.00 \\
(10.00- \\
75.00) \\
\end{array}$ & $\begin{array}{c}5.00 \\
(1.25- \\
65.00) \\
\end{array}$ & $\begin{array}{c}15.00 \\
(0.00- \\
30.00)\end{array}$ & $\begin{array}{c}25.00 \\
(12.50- \\
61.25) \\
\end{array}$ & $\begin{array}{c}62.50 \\
(46.25- \\
78.75)\end{array}$ & $50(0-90)$ \\
\hline $\operatorname{Ki67}(\%)^{\mathrm{a}}$ & $\begin{array}{c}60.00 \\
(52.50- \\
75.00)\end{array}$ & $\begin{array}{c}30.00 \\
(22.50- \\
40.00) \\
\end{array}$ & $\begin{array}{l}20.00 \\
(6.25- \\
30.00) \\
\end{array}$ & $\begin{array}{c}70.00 \\
(55.00- \\
70.00)\end{array}$ & $\begin{array}{c}32.50 \\
(28.75- \\
42.50) \\
\end{array}$ & $\begin{array}{c}40.00 \\
(35.00- \\
45.00) \\
\end{array}$ & $20(10-55)$ \\
\hline HER2, positive ${ }^{b}$ & $1(5.26)$ & $0(0.00)$ & $1(16.67)$ & $0(0.00)$ & $2(100.00)$ & $1(50.00)$ & $2(5.13)$ \\
\hline
\end{tabular}

a: median $(\mathrm{Q} 1-\mathrm{Q} 3)$, where $\mathrm{Q}=$ quartile $(1$ = first, 3 = third $)$

b: no. of cases $(\%)$

$\mathrm{ER}=$ Estrogen receptors, $\mathrm{PR}=$ Progesterone Receptors, Ki67 = proliferation index, HER2 = human epidermal growth factor 2 receptor 
Significant differences were identified for ER $(\%)(p=0.0051)$, PR $(\%)(p=0.0004)$, and Ki67 $(\%)(p=0.0010)$ when the BRCA1 group was compared to subjects with negative mutations (Table 3, Figure 1A, 1B, 1C). No other significant differences for comparisons of the other gene mutations groups with negative mutation subjects were observed ( $\mathrm{p}>0.05$ ) (Table 3, Figure $1 \mathrm{~A}, 1 \mathrm{~B}, 1 \mathrm{C})$.

BRCA1 c.3607C $>$ T mutation was diagnosed in seven patients, followed by mutations c.5266dupC (4 cases) and c. $181 \mathrm{~T}>\mathrm{G}$ ( 2 cases). $B R C A 1$ c. $3607 \mathrm{C}>\mathrm{T}$ mutation was the most common in the studied group and it was associated with TNBC type $(p<0.0001)$ in six of these cases (Table 4).

Of the 41 patients with pathogenic mutations, 5 had mutations in a second gene $(12.2 \%)$, 2 cases involving BRCA1 gene (associated $M E N$ gene and MUTYH gene), 2 cases involving CHEK2 gene (associated BLM gene and $R A D 50$ gene) and 1 case involving $B R C A 2$ gene (ATM gene) (Table 4). In one case a mutation in $C H E K 2$ gene was associated with VUS mutations in other 2 genes (ATM and BLM) (Table 4).

\section{Discussion}

This study provides information regarding the main deleterious variants with high and moderate penetrance involved in the pathogenesis of breast cancer in the population of North Western Romania, being the first study of its kind to our knowledge. It also provides information regarding the immunohistochemical features of the breast tumors in the mutation carriers, demonstrating that the association of some immunohistochemical features with certain mutations may entitle us to a genetic testing in some situations.

Recent studies emphasize the pathogenic implication of certain genes, such as PALB2 [15] and $C H E K 2$ [16] that were previously considered to have a moderate penetrance and a minor role in breast cancer.

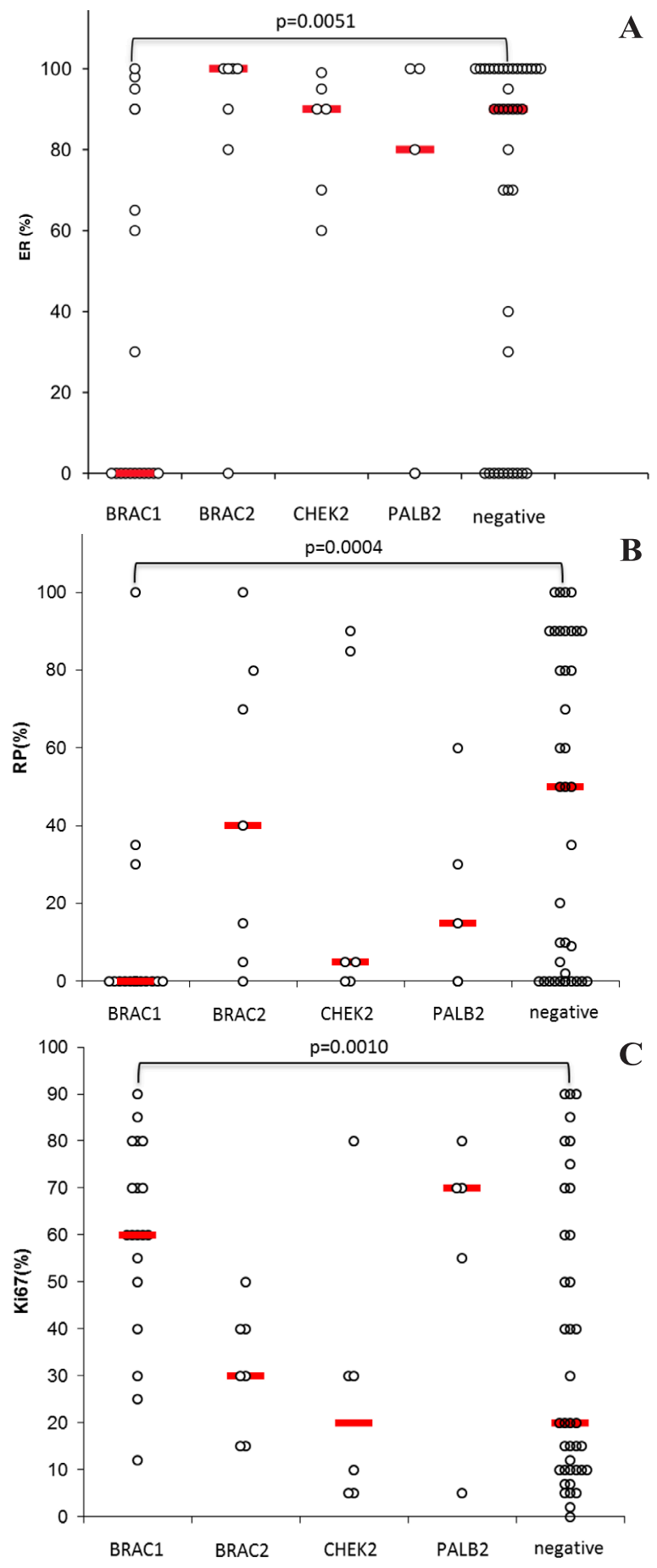

Figure 1. Immunohistochemical characteristics of breast cancer patients according to the groups of mutations compared with negativ group. $\mathrm{A}-\mathrm{ER}=$ Estrogen Receptors (\%); B - PR=Progesterone Receptors (\%) C $-\mathrm{Ki} 67=$ proliferation index (\%) 


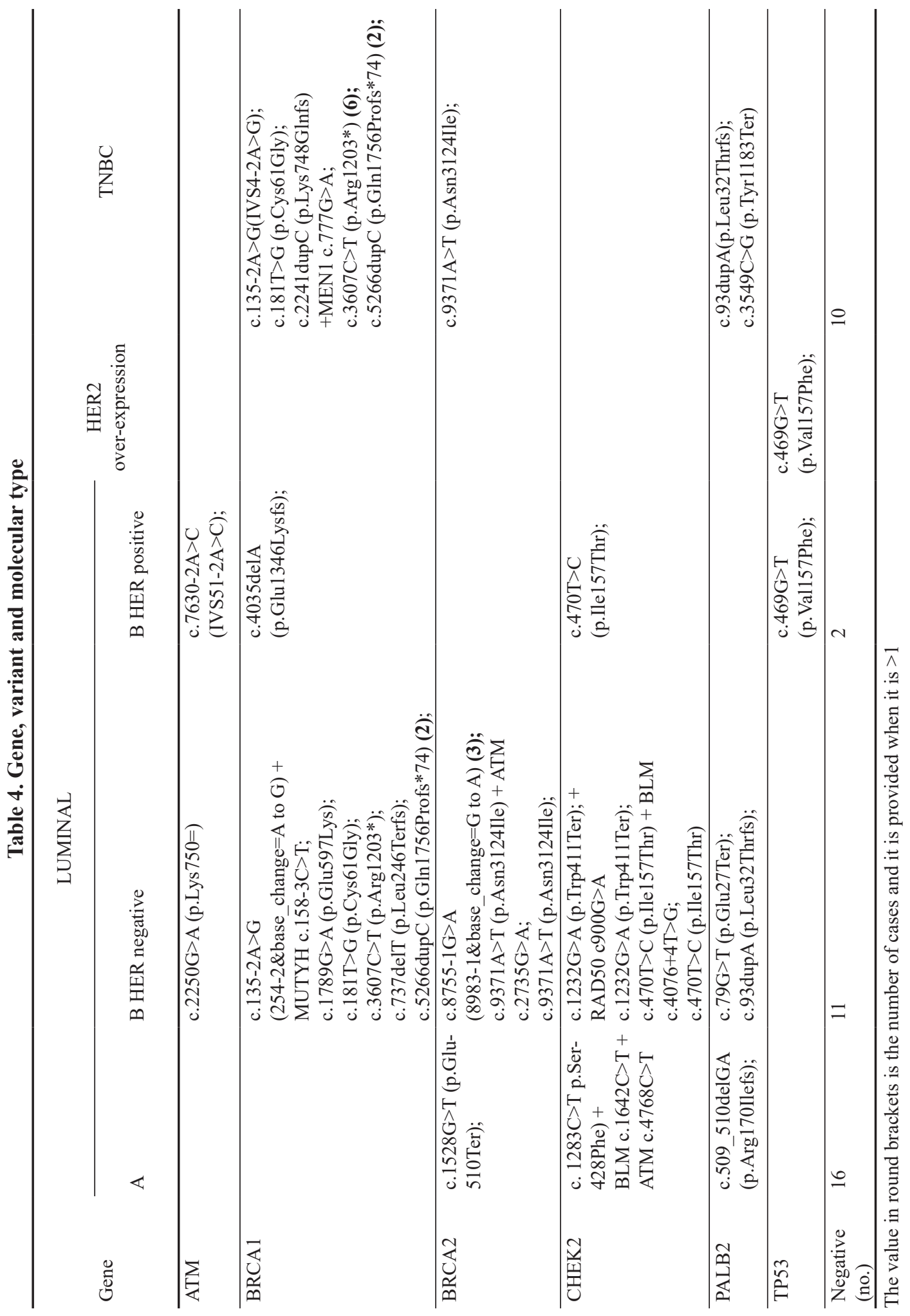




\section{BRCA1}

Our results showed an association of $B R C A 1$ mutations with a low percentage of ER, PR, an increased Ki67 index and a HER2 negative status when compared to the negative mutation group (Table 1, Figure 1). The results are similar to those published by Mavaddat et al. in a study conducted on 3797 patients with breast cancer and positive BRCA1 mutations, their immunohistochemical analysis revealing that $78 \%$ were ER-negative; 79\% were PR-negative; 90\% were HER2-negative and 69\% were TNBC [7]. In another study from Poland authors concluded that TNBC forms of breast cancer occur in up to $80 \%$ of patients with positive $B R C A 1$ mutations [17].

Also, patients with pathogenic $B R C A 1 \mathrm{mu}-$ tations associated poorly differentiated tumors (13 cases) or moderately differentiated tumors (6 cases), the results being similar to those in the literature [17].

Within the BRCA1 group in our study, we identified the $B R C A 1$ c. $3607 \mathrm{C}>\mathrm{T}$ mutation in 7 cases, $B R C A 1$ c.5266dupC mutation in 4 cases and $B R C A 1$ c. $181 \mathrm{~T}>\mathrm{G}$ mutation in 2 cases (Table 4). The BRCA1 c.5266dupC and c. $181 \mathrm{~T}>\mathrm{G}$ mutations were reported to be present in the north-eastern Romanian population in the only two studies conducted so far in our country $[18,19]$.

The BRCA1 c. $3607 \mathrm{C}>\mathrm{T}$ mutation was the most frequent variant reported, and has not been reported to date in the Romanian population. Furthermore, this mutation was associated with TNBC in 6 cases and all patients were from cities located in north-western Romania. This sequence change creates a premature translational stop signal at codon 1203 (p. Arg1203*) resulting in an absent or disrupted protein product [20].

\section{BRCA2}

BRCA2 positive breast tumors behave as sporadic breast carcinoma variants, usually expressing ER and PR, unlike positive BRCA1 cancers as demonstrated in our study, where only one patient was diagnosed with TNBC (BRCA2 c.9371A $>$ T) (Table 4). Similar results were obtained by Mavaddat et al. who examined 2392 patients with breast cancer and positive BRCA2 mutation and concluded that $23 \%$ were ER-negative, $36 \%$ were PR-negative, $87 \%$ were HER-negative and only $16 \%$ were triple-negative [7].

Patients with breast cancer and pathogenic BRCA2 mutations had histological patterns with a lower proliferation index compared to other classes of mutations being similar to sporadic breast cancer.

In our $B R C A 2$ group we diagnosed 7 mutation of which 3 cases had c.8755-1G $>$ A mutation, 3 cases had c. $9371 \mathrm{~A}>\mathrm{T}$ and c. $1528 \mathrm{G}>\mathrm{T}$ in one case (Table 4). BRCA2 c.8755-1G $>$ A mutation was described as pathogenic in a Czech report from 2008 [21] and $B R C A 2$ c. $9371 \mathrm{~A}>\mathrm{T}$ was described in several studies from Poland [22], but never reported in Romanian population.

\section{CHEK2}

Patients with CHEK2 mutations had increased levels of ER, similar to those from the group with negative mutation, but with lower values of RP, especially for the 3 cases with CHEK2 c.470T $>\mathrm{C}$ mutation, where $\mathrm{PR}$ ranged between $0-5 \%$. Data from the literature argue that CHEK2 mutations are associated with ER-positive types according to a study from 2009 conducted on Polish population [23], which is supported also by a recent article stating that the carriers of CHEK2 mutations associate luminal tumors rather than TNBC [9].

Although some studies associate CHEK2 c. $470 \mathrm{~T}>\mathrm{C}$ variant with invasive lobular carcinoma [24], in our study all the 3 patients carrying this mutation were diagnosed with invasive ductal carcinoma.

HER 2 was negative in 5 of the 6 cases, this data being in accordance with other studies on 
patients with $C H E K 2$ mutations and breast cancer (Table 4) [25].

Of the 6 patients with CHEK 2 mutations, 2 patients had bilateral breast carcinoma. Although this finding was interesting, due to the limited number of cases we cannot have a firm conclusion of this association, further studies being needed to clear up this question (Table 2). This possible correlation can be argued by a Danish study from 2014, in which the authors claim an increased risk of contralateral breast cancer in patients $C H E K 2$, but this risk was assessed only for 1100delC mutation which is the most common pathogenic variant of this gene [26].

\section{PALB2}

The subjects with $P A L B 2$ mutation from our study had the absence of HER2 expression as immunohistochemical characteristic, two of them were TNBC (Table 2 and 3).

Even though it did not reach statistical significance, it can be observed that the Ki 67 proliferation index is the highest in this group, even higher than in the BRCA1 mutation group (Table 3). Furthermore, in $80 \%$ of cases, PALB2 mutations were associated with poorly differentiated histological patterns suggesting an increased aggression and a worse outcome (Table 2). These results are consistent with other studies conducted on breast cancer patients with deleterious PALB2 mutations, which showed an association with TNBC in $33 \%$ [27] to $54 \%$ of cases, and proved that $P A L B 2$ mutation carriers had a worse prognosis and lower survival rates than other pathogenic mutations [28]. In a review from 2015 which totaled 1824 patients with TNBC from 12 studies, $1.2 \%$ of patients had deleterious variants in PALB2 gene [29].

\section{TP53}

The 2 patients with TP53 c.469G $>$ T mutation, had the overexpression of HER2 as immu- nohistochemical characteristic (Table 3 and 4). This observation is supported by other studies that have shown that breast cancer patients with positive TP53 mutation can associate HER2 overexpressing forms in up to $82 \%$ of cases [ 30 , 31].

Our results are consistent with those of Bougeard et al. who, in a study published in 2015, conducted on 127 breast cancer patients and positive TP53 mutations reported that HER 2 alone was positive in $55 \%$ of cases and $37 \%$ of cases were triple positive [31].

\section{ATM}

The 2 patients with ATM mutations had positive ER, PR and HER2 was positive in one case (Table 3 and 4).

Currently there are no available data about the correlation between tumor pathology subtype and ATM mutations carriers.

Only a few studies have demonstrated an association between the presence of ATM mutations in patients with breast carcinoma and HER2 overexpression both in vivo and in vitro $[32,33]$, but the studies on this gene are still at the beginning.

\section{Conclusion}

Our research revealed a new $B R C A 1$ mutation which has not been reported to date in the North-Western Romanian population, BRCA1 c. $3607 \mathrm{C}>\mathrm{T}$, as the most frequent in this population. To date, the only studies conducted in this population argue that c.5266dupC is the most common variant in this region. The $B R C A 1$ c.3607C $>\mathrm{T}$ variant associates TNBC type, which is consistent with the general immunohistochemical profile of patients with breast cancer and positive $B R C A 1$ mutation.

Regarding BRCA2 mutations both c.8755$1 \mathrm{G}>\mathrm{A}$ and c.9371A $>\mathrm{T}$ variants were never described in Romanian population and the data 
from the Eastern European countries for these two mutations are confined, the immunohistochemical pattern being similar to the sporadic forms of breast cancer.

For the rest of the mutations our results regarding their correlation with immunohistochemical features were similar to the data reported by other studies, but the small number of cases makes it difficult to establish some pertinent conclusions. Subsequent studies on a larger number of patients will be able to clarify whether CHEK2 mutations are associated with multifocal or bilateral forms, or whether ATM and TP53 mutations have the overexpression of HER2 as an immunohistochemical feature.

The main limitation of our study is that it is a retrospective study addressing only the North-Western region of Romania. Maybe a future multicenter study addressing more regions in Romania will gather more pathogenic variants that could create the premises for stronger conclusions.

\section{Abbreviations}

ER - estrogen receptor

$\mathrm{PR}$ - progesterone receptor

HER2 - human epidermal growth factor 2 receptor

HBOC - Hereditary Breast and Ovarian Cancer Syndrome

NGS - Next Generation Sequencing

Ki67 - proliferation index

TNBC - Triple Negative Breast Cancer

VUS - Variants with Unknown significance

\section{References}

1. Ferlay J, Steliarova-Foucher E, Lortet-Tieulent J, Rosso S, Coebergh JW, Comber H, et al. Cancer incidence and mortality patterns in Europe: estimates for 40 countries in 2012. Eur J Cancer. 2013; 49(6):1374-403. DOI: 10.1016/j.ejca.2012.12.027
2. Hall JM, Lee MK, Newman B, Morrow JE, Anderson LA, Huey B, et al. Linkage of early-onset familial breast cancer to chromosome 17q21. Science. 1990; 250(4988):1684-9. DOI: 10.1126/science.2270482

3. Wooster R, Neuhausen SL, Mangion J, Quirk Y, Ford $\mathrm{D}$, Collins N, et al. Localization of a breast cancer susceptibility gene, BRCA2, to chromosome 13q12-13. Science. 1994; 265(5181):2088-90. DOI: $10.1126 /$ science.8091231

4. Kurian AW, Kingham KE, Ford JM. Next-generation sequencing for hereditary breast and gynecologic cancer risk assessment. Curr Opin Obstet Gynecol. 2015; 27(1):23-33. DOI: 10.1097/GCO.0000000000000141

5. Hilbers FS, Vreeswijk MP, van Asperen CJ, Devilee P. The impact of next generation sequencing on the analysis of breast cancer susceptibility: a role for extremely rare genetic variation? Clin Genet. 2013; 84(5):407-14. DOI: $10.1111 /$ cge. 12256

6. Sharma P, Klemp JR, Kimler BF, Mahnken JD, Geier LJ, Khan QJ, et al. Germline BRCA mutation evaluation in a prospective triple-negative breast cancer registry: implications for hereditary breast and/or ovarian cancer syndrome testing. Breast Cancer Res Treat. 2014; 145(3):707-14. DOI: 10.1007/s10549-014-29800

7. Mavaddat N, Peock S, Frost D, Ellis S, Platte R, Fineberg $\mathrm{E}$, et al. Cancer risks for BRCA1 and BRCA2 mutation carriers: results from prospective analysis of EMBRACE. J Natl Cancer Inst. 2013; 105(11):812-22. DOI: $10.1093 /$ jnci/djt095

8. Zaky SS, Lund M, May KA, Godette KD, Beitler JJ, Holmes LR, et al. The negative effect of triple-negative breast cancer on outcome after breast-conserving therapy. Ann Surg Oncol. 2011; 18(10):2858-65. DOI: 10.1245/s10434-011-1669-4

9. Domagala P, Jakubowska A, Jaworska-Bieniek K, Kaczmarek K, Durda K, Kurlapska A, et al. Prevalence of Germline Mutations in Genes Engaged in DNA Damage Repair by Homologous Recombination in Patients with Triple-Negative and Hereditary Non-Triple-Negative Breast Cancers. PLoS One. 2015; 10(6):e0130393. DOI: 10.1371/journal.pone.0130393

10. Morris JL, Gordon OK. Positive results : making the best decisions when you're at high risk for breast or ovarian cancer. Amherst, N.Y.: Prometheus Books; 2010. 395 p. p.

11. Daly MB, Pilarski R, Axilbund JE, Berry M, Buys SS, Crawford B, et al. Genetic/Familial High-Risk Assessment: Breast and Ovarian, Version 2.2015. J Natl Compr Canc Netw. 2016; 14(2):153-62. DOI: 10.6004/ jncen.2016.0018

12. Chennagiri N, White EJ, Frieden A, Lopez E, Lieber DS, Nikiforov A, et al. Orthogonal NGS for High Throughput Clinical Diagnostics. Sci Rep. 2016; 6:24650. DOI: $10.1038 /$ srep24650 
13. Unger MA, Nathanson KL, Calzone K, Antin-Ozerkis D, Shih HA, Martin AM, et al. Screening for genomic rearrangements in families with breast and ovarian cancer identifies BRCA1 mutations previously missed by conformation-sensitive gel electrophoresis or sequencing. Am J Hum Genet. 2000; 67(4):841-50. DOI: $10.1086 / 303076$

14. Weissgerber TL, Milic NM, Winham SJ, Garovic VD. Beyond bar and line graphs: time for a new data presentation paradigm. PLoS Biol. 2015; 13(4):e1002128. DOI: 10.1371/journal.pbio.1002128

15. Kwong A, Chen JW, Shin VY. A new paradigm of genetic testing for hereditary breast/ovarian cancers. Hong Kong Med J. 2016; 22(2):171-7.

16. Weischer M, Bojesen SE, Tybjaerg-Hansen A, Axelsson CK, Nordestgaard BG. Increased risk of breast cancer associated with CHEK2*1100delC. J Clin Oncol. 2007; 25(1):57-63. DOI: 10.1200/JCO.2005.05.5160

17. Domagala P, Huzarski T, Lubinski J, Gugala K, Domagala W. Immunophenotypic predictive profiling of BRCA1-associated breast cancer. Virchows Arch. 2011; 458(1):55-64. DOI: 10.1007/s00428-010-0988-3

18. Negura L, Uhrhammer N, Negura A, Artenie V, Carasevici E, Bignon YJ. Complete BRCA mutation screening in breast and ovarian cancer predisposition families from a North-Eastern Romanian population. Fam Cancer. 2010; 9(4):519-23. DOI: 10.1007/s10689-0109361-6

19. Burcos T, Cimponeriu D, Ion DA, Spandole S, Apostol P, Toma M, et al. Analysis of several BRCA1 and BRCA2 mutations in a hospital-based series of unselected breast cancer cases. Chirurgia (Bucur). 2013; 108(4):468-72.

20. Walsh T, Casadei S, Lee MK, Pennil CC, Nord AS, Thornton AM, et al. Mutations in 12 genes for inherited ovarian, fallopian tube, and peritoneal carcinoma identified by massively parallel sequencing. Proc Natl Acad Sci U S A. 2011; 108(44):18032-7. DOI: 10.1073/ pnas. 1115052108

21. Machackova E, Foretova L, Lukesova M, Vasickova P, Navratilova M, Coene I, et al. Spectrum and characterisation of BRCA1 and BRCA2 deleterious mutations in high-risk Czech patients with breast and/or ovarian cancer. BMC Cancer. 2008; 8:140. DOI: 10.1186/14712407-8-140

22. Wojcik P, Jasiowka M, Strycharz E, Sobol M, Hodorowicz-Zaniewska D, Skotnicki P, et al. Recurrent mutations of BRCA1, BRCA2 and PALB2 in the population of breast and ovarian cancer patients in Southern Poland. Hered Cancer Clin Pract. 2016; 14:5. DOI: 10.1186/s13053-016-0046-5

23. Cybulski C, Huzarski T, Byrski T, Gronwald J, Debniak T, Jakubowska A, et al. Estrogen receptor status in CHEK2-positive breast cancers: implications for chemoprevention. Clin Genet. 2009; 75(1):72-8. DOI: 10.1111/j.1399-0004.2008.01111.x

24. Liu C, Wang Y, Wang QS, Wang YJ. The CHEK2 I157T variant and breast cancer susceptibility: a systematic review and meta-analysis. Asian Pac J Cancer Prev. 2012; 13(4):1355-60. DOI: 10.7314/APJCP.2012.13.4.1355

25. Huszno J, Budryk M, Kolosza Z, Tecza K, Pamula Pilat J, Nowara E, et al. A Comparison between CHEK2*1100delC/I157T Mutation Carrier and Noncarrier Breast Cancer Patients: A Clinicopathological Analysis. Oncology. 2016; 90(4):193-8. DOI: 10.1159/000444326

26. Kriege M, Hollestelle A, Jager A, Huijts PE, Berns EM, Sieuwerts AM, et al. Survival and contralateral breast cancer in CHEK2 1100delC breast cancer patients: impact of adjuvant chemotherapy. Br J Cancer. 2014; 111(5):1004-13. DOI: 10.1038/bjc.2014.306

27. Cybulski C, Kluzniak W, Huzarski T, Wokolorczyk D, Kashyap A, Jakubowska A, et al. Clinical outcomes in women with breast cancer and a PALB2 mutation: a prospective cohort analysis. Lancet Oncol. 2015; 16(6):638-44. DOI: 10.1016/S1470-2045(15)70142-7

28. Heikkinen T, Karkkainen H, Aaltonen K, Milne RL, Heikkila P, Aittomaki K, et al. The breast cancer susceptibility mutation PALB2 1592delT is associated with an aggressive tumor phenotype. Clin Cancer Res. 2009; 15(9):3214-22. DOI: 10.1158/1078-0432.CCR08-3128

29. Couch FJ, Hart SN, Sharma P, Toland AE, Wang X, Miron P, et al. Inherited mutations in 17 breast cancer susceptibility genes among a large triple-negative breast cancer cohort unselected for family history of breast cancer. J Clin Oncol. 2015; 33(4):304-11. DOI: 10.1200/JCO.2014.57.1414

30. Wilson JR, Bateman AC, Hanson H, An Q, Evans G, Rahman N, et al. A novel HER2-positive breast cancer phenotype arising from germline TP53 mutations. J Med Genet. 2010; 47(11):771-4. DOI: 10.1136/ jmg.2010.078113

31. Bougeard G, Renaux-Petel M, Flaman JM, Charbonnier C, Fermey P, Belotti M, et al. Revisiting Li-Fraumeni Syndrome From TP53 Mutation Carriers. J Clin Oncol. 2015; 33(21):2345-52. DOI: $10.1200 /$ JCO.2014.59.5728

32. Stagni V, Manni I, Oropallo V, Mottolese M, Di Benedetto A, Piaggio G, et al. ATM kinase sustains HER2 tumorigenicity in breast cancer. Nat Commun. 2015; 6:6886. DOI: $10.1038 /$ ncomms 7886

33. Eccles DM, Li N, Handwerker R, Maishman T, Copson ER, Durcan LT, et al. Genetic testing in a cohort of young patients with HER2-amplified breast cancer. Ann Oncol. 2016; 27(3):467-73. DOI: 10.1093/annonc/ mdv592 